\title{
Study on Increasing Performances of Hybrid Composite Through Pull Out Compression Test Assessement
}

\author{
RALUCA MAIER*
}

${ }^{1}$ Romanian Research and Development Institute for Gas Turbine COMOTI, 220D Iuliu Maniu Av., Bucharest Romania

\begin{abstract}
The exhaustive use of light advanced polymer composites into the development of the future high-efficiency long-range commercial aircrafts (primary) structures for increasing strength while decreasing weight for lower fuel consumption and less pollution has attracted great attention in the last decade. In this context, solutions for the integration and joining composites into the aircraft structures metallic sub-assemblies or components, while providing the necessary strength to sustain heavily loaded joints, are urgently required. The paper comes to meet an area of interest for many researchers and large integrators and manufacturers, by presenting several type of metallic join geometrical designs, along with metallic joint part integration solutions into a composite structure directly during production. Performances evaluation of the developed metallic join geometrical designs was performed in static regime by means of ,pull-out" compressive tests. The paper focuses on the strength of the hybrid metallic/advanced polymer composites joints. It was concluded that an efficient design of the metallic joint and a proper transition from hybrid to the composite structure can lead to proper integration solutions while assuring safety requirements.
\end{abstract}

Keywords: metallic inserts, geometrical design, hybrid carbon reinforced polymeric composite, metallic joints, vacuum assisted thermal processing

\section{Introduction}

In the last decade, here has been a massive tendency towards substitutions of metal parts of structures with parts made of composite materials. The increasing requirements for weight reduction demand more and more the use of composite material in industrial applications. Therefore, the use of composite materials has been steadily increasing in recent years in aeronautics, spacecraft design and civil engineering applications, offering advantages in weight reduction, strength, and stiffness when compared to conventional materials. In this context, joining metallic to composite structures is necessary. However, a series of new problems arise, as the materials used in one structure have very different mechanical properties. A design of joining a metal and a composite part is not simple. There are many types of the joining, but the achievement of economy, reliability, durability and high strength of the composite/metal joint is always a problem [1-3]. To utilize composites fully, a thorough understanding of the joint strength is required to prevent premature failure of a component at an interface. The use of adhesively bonded joints in structural applications offers considerable advantages compared with traditional forms of joining, such as bolting, riveting, and welding [4, 5, 6]. Especially for joining of fiber-reinforced polymer (FRP) composites to other structural materials such as metal, adhesive bonding enables light weight and cost effective design [7]. One of the predominant concerns for engineers in using adhesive bonding is to optimize the adhesion strength. Thus, it is essential to understand adhesion mechanisms and investigate the influence of each mechanism on the adhesion strength since it can fundamentally allow us to reach the formation of strong and reliable adhesive joints. Among a number of mechanisms that account for the adhesion phenomenon, it has been well-known that adsorption and mechanical interlock are the dominant mechanisms that contribute to the adhesion strength of metal-polymer interfaces $[4,5]$. When it comes to complex structures employed in aeronautic applications, high standards are compulsory in order to guarantee safety in both nominal functioning

*email: raluca.maier@comoti.ro 
regime as well as in critical cases. Thus, both high strength and ductility to sustain specific local deformations are required for the hybrid composite/metallic joints that prove to be challenging to achieve through conventional composite structures.

With this background, this paper reports the results of a systematic investigation starting from analysing the influence of the geometrical design of the metallic join on the adhesion strength but also on the hybrid composite /metallic joints deformation field. Furthermore, two types of metallic materials were used for the joints, to analyse the response and failure characteristics between the metal and the composite. The effect of the metallic insertion geometry and roughness on the hybrid carbon fibrereinforced epoxy composites/metallic joint strength was determined also, performing ,pull-out” static compression tests.

\section{Materials and methods}

\section{Materials and sample preparation}

In order to investigate the hybrid composite metallic joints adhesion strength and fracture deformations 25 coupons were manufactured and tested. Three different metallic insertion geometries were designed using Solid Edge V20. Figure 1 presents these metallic insertions geometrical designs analysed.
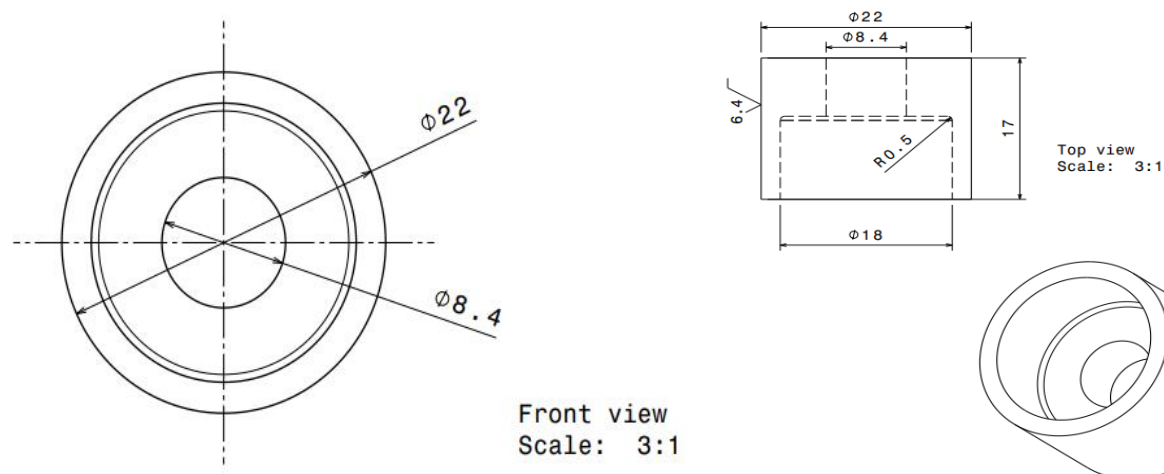
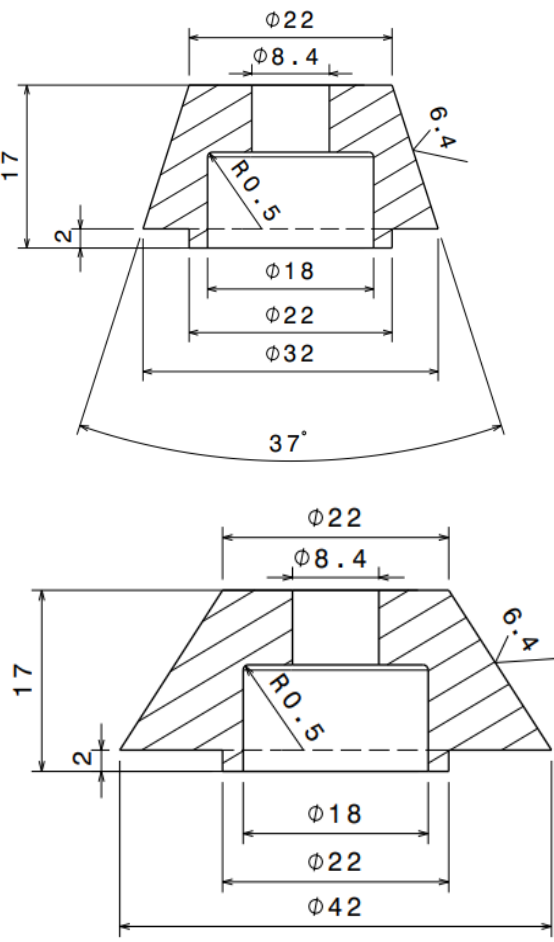

Front view Scale: $3: 1$

a

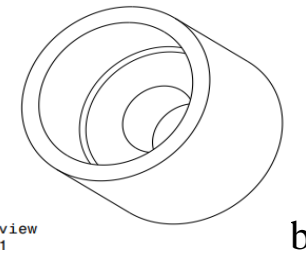

b

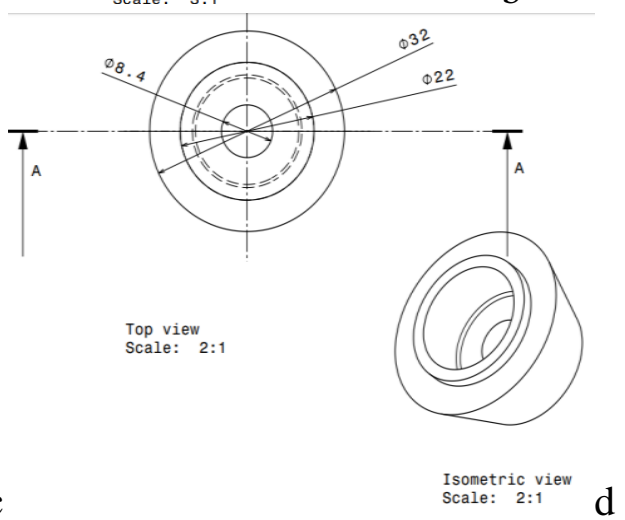

Section view A-A Scale: $2: 1$

$\mathrm{C}$

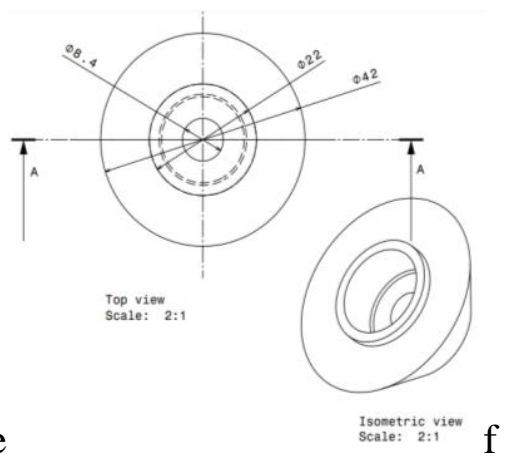

Figure 1. Metallic insertions geometrical designs a) Design 1; b) Design 2;

c) Design 3; d) section view of the Design 2; e) section view of the Design 3 
Metallic insertions (bush type) were mechanically machined using 5 axes milling machine. For Design 1 (figure 1-a, b), metallic insertions were performed in OLC45 steel and three external surface roughness (Ra: 1.6; 3.2 and respectivelly 6.4$)$ were tested in order to determine the influence of surface treatment on the adhesion performances at composite/metal interface. For Design 2 (figure 1-c, d) and respectively Design 3 (figure 1-e, f) metallic insertions were made from aluminium 2024-T3 (A195/Cu4/Mg1) alloy with an external surface roughness Ra of 6.4. Holes were performed in each preimpregnated carbon fiber-reinforced epoxy polymer layer and metallic insertions were embedded within layers, as showed in figure 2 images, where are displayed the stages of hybrid composite /metallic joints sample laminates preparation. The circular holes maximum diameters varied from one design to another, from $22 \mathrm{~mm}$ (Design 1), $32 \mathrm{~mm}$ (Design 2) and $42 \mathrm{~mm}$ (Design 3). The composite material is a Hexply product, based on $42_{\mathrm{wt}} \%$ M49 high toughened epoxy blend $\left(1,18 \mathrm{~g} / \mathrm{cm}^{3}\right.$ density) with excellent tack and drap, reinforced by a fabric bidirectional network (twill2x 2 type) of high strength carbon $3 \mathrm{~K}$. 63 preimpregnated carbon fiber-reinforced epoxy polymer layers of $280 \times 175 \mathrm{~mm}$ each were used to build up the necessary composite laminate thickness of $17 \mathrm{~mm}$ (corresponding to the metallic insertions heights).

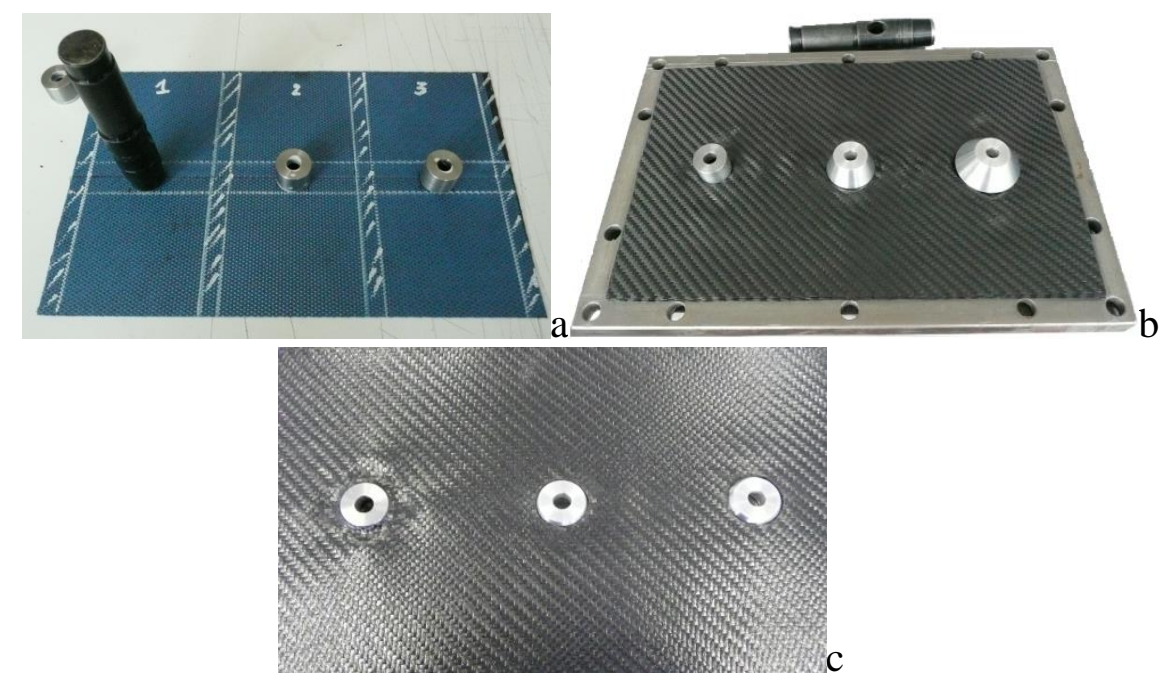

Figure 2. Stages of hybrid composite /metallic joints sample laminates preparation

The assambly laminates were covered with pell ply, release film, breather and vacumed bagded. The curing process was perforemed in a oven under -0.9 bars vacuum, at $140{ }^{\circ} \mathrm{C}$ (up to isothermal with an increase of temperature of $3{ }^{0} \mathrm{C} / \mathrm{min}$.), cured for $20 \mathrm{~h}$, and afterwards a cooling rate of $4{ }^{0} \mathrm{C} / \mathrm{min}$. was considered).

\section{Test of hybrid FRP coupons}

A total of 25 ,pull-out” compressive tests using coupon specimens cut from laboratory size panels were conducted to determine the effective mechanical properties of hybrid FRP composites. Samples for ,pull-out” compressive testing had $80 \times 40 \mathrm{~mm}$, with a thickness of $17 \mathrm{~mm}$. 5 specimens for each metallic insertion geometrical design were tested. „Pull-out” compressive tests were performed on a hydraulic universal testing machine Instron $8802(250 \mathrm{kN}$ cellule force $)$, using a constant cross-speed of $2 \mathrm{~mm} \cdot \mathrm{min}^{-1}$. Tests were done at room temperature, humidity RT $45 \%$ (4h conditioning), up to fracture, that is ,pull-out" of the metallic insertion from the composite structure. Figure 3 presents images of Design 1 hybrid metallic/composite testing sample upper (figure 3 a) and bottom (figure $3 \mathrm{~b}$ ) testing side, along with the dedicated testing device, mounted on the Instron 8802 testing machine (figure $3 \mathrm{c}$, d). A special device was designed and manufactured in order to perform these tests (figure $3 \mathrm{c}, \mathrm{d}$ ), comprising a 180x60x10 mm plate mounted (fixed) on the lower grip of the testing machine, a mandrel (15 mm diameter and $33 \mathrm{~mm}$ height) screwed in the middle of the previous described plate fixed on the 
lower grip, and a $124 \times 80 \times 35 \mathrm{~mm}$ mobile plate to allow alignment of the sample prior to testing. This later plate has a middle $25 \mathrm{~mm}$ hole (higher than $22 \mathrm{~mm}$, as being the diameter of the cylindrical Design 1 metallic insertion) which allows releasing the metallic insertion after ,pull-out" from the hybrid composite/metallic structure. For Design 2 and respectively Design 3, the lower grip plate was eliminated.
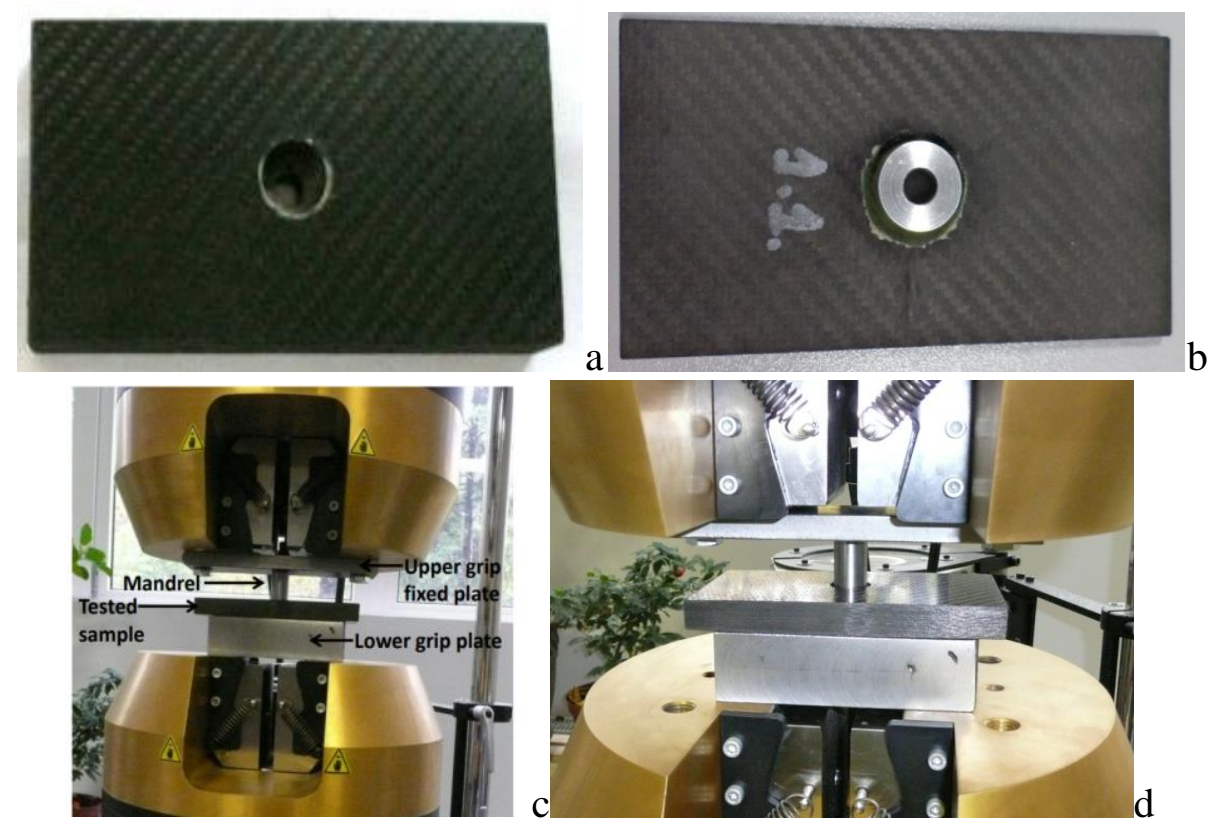

Figure 3 Metallic insertions Design 1 hybrid metallic/composite sample a) upper and b) bottom tested side images; c) during compression ,pull-out" testing sample; d) dedicated testing device, mounted on the Instron 8802 testing machine

\section{Results and discussions}

The ,pull-out” compressive tests results, showing hybrid carbon fibre-reinforced epoxy composites/metallic joint strength are presented in figure 4 (for metallic insertions - Design 1). Results showed a net influence of the surface metallic joint roughness on the interface metallic/composite joint strength. Increasing roughness $\mathrm{Ra}$ from 1.6 to 3.2 and respectivelly 6.4 , leads to a rise in compressive load.

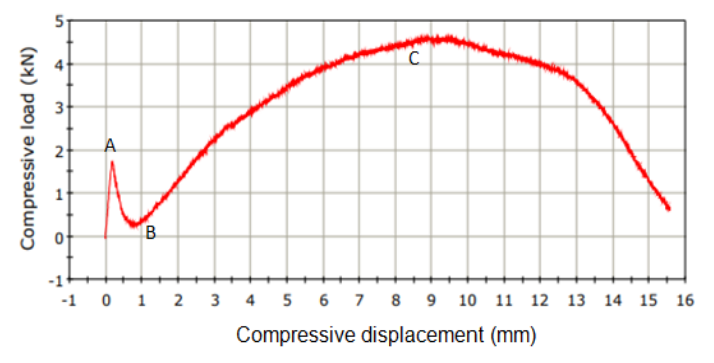

a

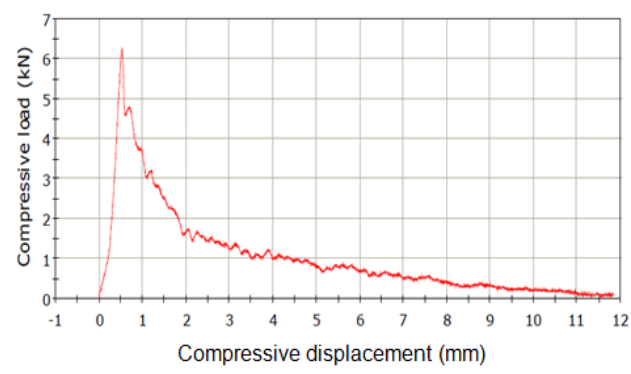

Mater. Plast., 57 (1), 2020, 329-335

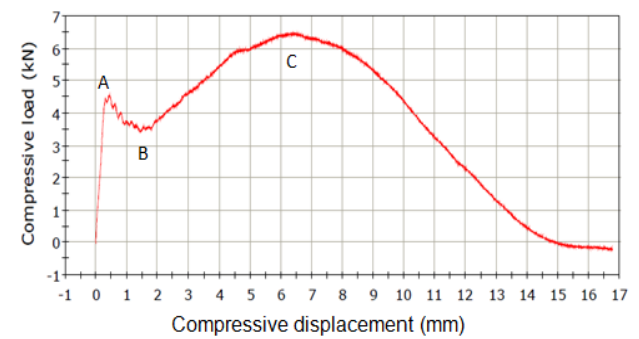

Figure 4. Load-displacement curves for representative Design 1 hybrid metallic/composite tested samples (function of surface roughness of the metallic insertion) a) $\mathrm{Ra}=1.6$; b) $\mathrm{Ra}=3.2$; c) $\mathrm{Ra}=6.4$ c 
This type of behaviour was already reported in privious studies $[7,8,9]$ where 2 points of inflection characterize these curves. More than one failure point is usually observed. The curve starts with a linear portion. The slope of this linear portion of the bearing stress-bearing strain curve is called the bearing chord stiffness. Then an initiation of damage triggers a non-linear part of the curve (Point A in figure 4, a). Shortly after, a bearing failure causes the load to drop (initial failure Point B, figure 4, a). After this point, a bolted joint of composite material can usually carry an additional load, experiencing a new maximum (ultimate failure, Point $\mathrm{C}$ in figure 4, a). In this case the bearing strength of the bolted joint depends on how the failure is defined. Second and last characteristic points (B and C) generate initial and ultimate bearing strengths, respectively. During the present work, the strength of the hybrid composite/steel joints is defined by ultimate strength (the second maximum point at ultimate failure. Fracture mechanims involved in ,pull-out" compressive tests are very complex, as showed also on the load-displacement curves. Figure 5 presents the hybrid carbon fibre-reinforced composites/metallic joints fractured samples for Design 1.
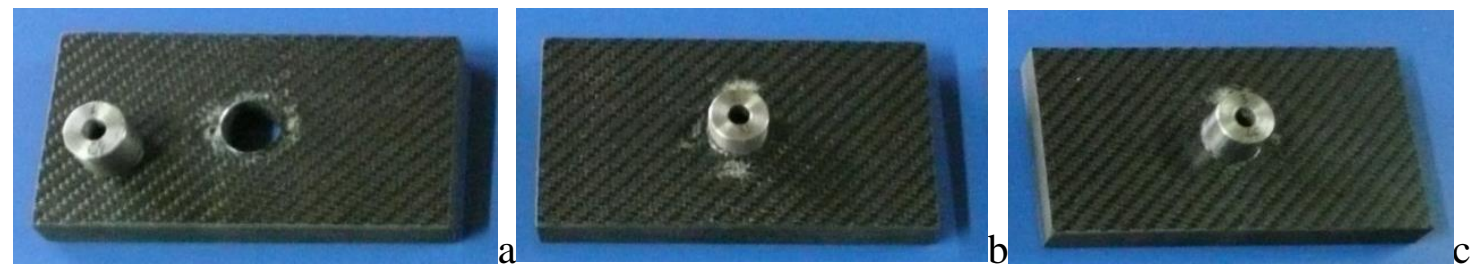

Figure 5. Hybrid carbon fibre-reinforced composites/metallic joints fractured samples (Design 1): a) $\mathrm{Ra}=1.6$; b) $\mathrm{Ra}=3.2$; c) $\mathrm{Ra}=6.4$

The adhesion strength, as the required energy for fracture, is related to the metallic insertion external surface area, metallic insertion roughness as well as type, since during hybrid structure laminates manufacturing thermal expansion coefficients CTE mismatch can appear between insertion and composite material. Increased adhesion could be furthermore obtained by inducing radial controlled geometrical „defects" within the metallic insertion external surface area, increasing surface roughness (Ra) or filleting the area. Metallic insertion external surface sandblasting can be used for increasing surface roughness, higher blasting intensity (e.g. higher blasting pressure, higher times) leading to a higher surface roughness. Furthermore, the ,pull-out” compressive tests results for Design 2 and respectively Design 3 hybrid carbon fibre-reinforced epoxy composites/metallic joints, with an external surface roughness Ra of 6.4, are presented in figure 6 .
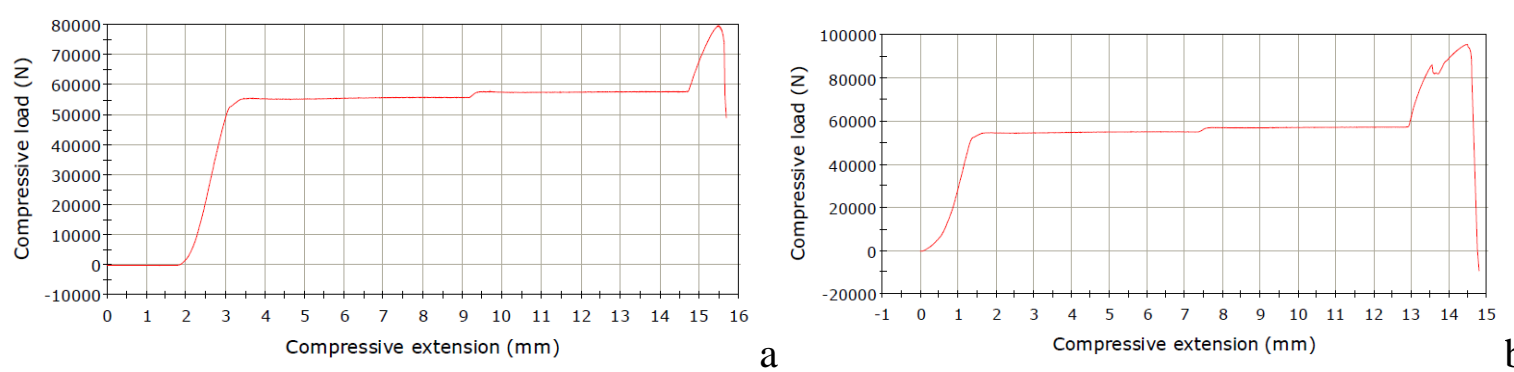

Figure 6. Load-displacement curves for representative Design 2 (a) and respectively Design 3 (b) hybrid metallic/composite tested samples $(\mathrm{Ra}=6.4)$

Results showed an important improvement of the hybrid carbon fibre-reinforced epoxy composites/metallic joints, due to the design optimization (Designs 2 and 3 in comparison with Design 1). The ,pull-out” compressive strength is more than ten times higher when passing from Design 1 to Design 2. This is related to increasing contact area between metallic insertion and the carbon reinforced epoxy composite thus increasing adhesion strength. Equally, displacements are more than two times higher, but this fact is also related to the aluminium alloy deformations during ,pull-out” tests, when compared to the steel material for the metallic insert. Nevertheless, the geometrical design of the metallic 
inserts and the configuration of the hybrid metallic/composite structure is strictly related to the main loading composite structure that shall be integrated in a sub-assembly.

Likewise, it was showed that increasing the maximum diameter of the metallic insertion when passing from Design 2 to Design 3 and allowing increase the embedment loading area the adhesion strength of the hybrid carbon fibre-reinforced epoxy composites/metallic joint is increased with $9 \%$. Results obtained showed that an appropriate design can lead to about 1 tone loading bearing strength for hybrid carbon fibre-reinforced epoxy composites/metallic joints.

Table 1 below shows a synopsis of results obtained on the three tested metallic insertions geometrical designs.

Table 1. Summary of results obtained in static regime (compression) on the hybrid metallic/carbon reinforced polymer composite tested samples, embedding the three tested metallic insertions geometrical designs

\begin{tabular}{|c|c|c|c|c|}
\hline Configuration & $\begin{array}{c}\text { Maximum } \\
\text { compression load } \\
{[\mathbf{k N}]}\end{array}$ & $\begin{array}{c}\text { Compression extension } \\
\text { at Maximum } \\
\text { compression load } \\
{[\mathbf{m m}]}\end{array}$ & $\begin{array}{c}\text { Local Peak Maximum } \\
\text { (Compression Load } \\
\text { 10\% change) } \\
{[\mathbf{k N}]}\end{array}$ & $\begin{array}{c}\text { Compression } \\
\text { displacement at Local } \\
\text { Peak Maximum } \\
\text { (Compression Load 10\% } \\
\text { change) } \\
{[\mathbf{m m}]}\end{array}$ \\
\hline Design 1.1 [Ra 1.6] & 4.61 & 9 & 1.73 & 0.19 \\
\hline Design 1.2 [Ra 3.2] & 6.47 & 6.4 & 4.57 & 0.44 \\
\hline Design 1.3 [Ra 6.4] & 6.25 & 0.54 & 6.25 & 0.54 \\
\hline Design 2 [Ra 6.4] & 79.63 & 15.46 & 79.63 & 15.46 \\
\hline Design 3 [Ra 6.4] & 95.38 & 14.47 & 95.38 & 14.47 \\
\hline
\end{tabular}

In comparison to single-material components, mixed metal-composite structural elements exhibit differences in the constitutive law, thermal or hydrothermal response and failure characteristics between the metal and the composite. Thus, materials selection for the metallic inserts is also a critical parameter in addition to the geometrical design. Large thermal mismatch stresses between metal insertion and composite can arise if improper materials, designs or structural parameters are defined.

High quality structural carbon OLC 45 steel was initially chosen due to its strength and relatively low coefficient of linear thermal expansion, CTE ( $\alpha$ varies from $11 \times 10^{-6} / \mathrm{K}$ to $15 \times 10^{-6} / \mathrm{K}$ on a temperature range from 25 to $700{ }^{\circ} \mathrm{C}$ ), when compared to aluminium 2024-T3 (A195/Cu4/Mg1) alloy $(\alpha$ $\left.=24 \times 10^{-6} / \mathrm{K}\right)$. Composite material generally exhibit very low coefficient of linear thermal expansion $(\alpha$ $=1 \times 10^{-6} / \mathrm{K}$ ), thus choosing a low CTE for the metallic insertion is important in order to avoid stress concentrations at composite/metallic insertion interface due to large thermal CTE mismatches. These zones of high stresses can induce damage initiation and growth, leading to fracture onset and ultimately failure. Consequently, in order to use such composite-metal joints in an optimal way, a thorough characterization of their mechanical and failure behaviour is required. Nevertheless, more industrial applications use aluminium alloys components or insertions, due to their low weigth benefit, thus, the study on this type of alloy is also justified. Future investigations of the present study shall analyse titanium alloys (aerospace grade) metallic insertions embeded in CFRP composite structures, as despite their higher costs, the joint offers clearlly some advanteges: low density $\left(4.42 \mathrm{~g} / \mathrm{cm}^{3}\right)$, low CTE $(\alpha=8.6$ x $\left.10^{-6} / \mathrm{K}\right)$, high strength, low weight ratio, outstanding corrosion resistance, high fatigue resistance.

\section{Conclusions}

The results of this study showed that high structural, mechanical performances can be obtained by proper geometrical and structural design definition of the metallic inserts. Furthermore, particular attention must be paid to surface preparation and suitable interaction between the adhesive and substrate to ensure joint longevity. Likewise, choosing the optimum metallic insert-composite materials is a critical design step, in order to mitigate large thermal mismatch stresses that can arise if improper materials, designs or structural parameters are defined. Hybrid structures with special geometrical designs, comprising carbon fiber reinforced polymer composite with low CTE and high strength metallic 
inserts were developed, showing high interface performances. Equally, for specific applications where deformation is needed to avoid or delay critical failure, special geometrical designs were defined. It was concluded that an efficient design and a proper material choice, surface roughness of the metallic joint of the hybrid composite structure can lead to proper integration solutions while assuring safety requirements.

\section{References}

1. CROSKY, A., KELly, D., LI, R., LEGRAND, X., HUONG, N., UJJIN, R., Compos. Struct., 76, 2006, p.260.

2. GAY, D., HOA, S.V., TSAI, S.W., Composite Materials - Design and Application, Edition 1, CRC Press LLC, Boca Raton, 2003, p.430

3. ICTEN, B. M., KARAKUZU, R., TOYGAR, M. E, Compos. Struct., 73, 2006, p.443.

4. KINLOCH, A. J., Adhesion and Adhesives: Science and Technology, Chapman and Hall, NY. 1987.

5. D.E. PACKHAM, Handbook of Adhesion (Polymer Science \& Technology), Edition 1, Published by Addison Wesley Longman, Longman, UK, 1992, p.98.

6. MA, Z., QI, Y., LIU, W., Math. Biosci. Eng., 16 nr.5, 2019, p.4213.

7. SUN, X., STEPHENS, E., HERLING, D., Static and fatigue strength evaluations for bolted composite/steel joints for heavy vehicle chassis components, Proceedings of the $4^{\text {th }}$ Annual SPE automotive Composite Conference, Commercial Transport Session, Brookfied, CT, 2004, edited by Society of Plastics Engineers, p. 1.

8. KELLY, D., LI, R., WILlGOSS, R., CROSKY, A., Improvement of Bearing Strength of Mechanically Fastened Composite Joints Using Fiber Steering, Proceedings of the $48^{\text {th }}$ International SAMPE Symposium, Long Beach, California, 2001, p. 2495.

9. TONG, L., Compos. PART A-Appl. S., 31, 2000, p.609.

Manuscript received: 29.10 .2019 